\title{
Single position lateral lumbar interbody fusion and pedicle screw fixation: preliminary experience and perioperative results
}

\author{
John Choi ${ }^{1}$, Isaac Rhee ${ }^{2}$, Mehul Sakar ${ }^{1}$, Isaac Park², Joseph Maalouly ${ }^{1}$ \\ 'Department of Orthopaedic Surgery and spine surgery, Spine Ortho Clinic, The Bays Hospital, VIC 3931, Australia. \\ ${ }^{2}$ Melbourne Medical School, University of Melbourne, VIC 3010, Australia.
}

Correspondence to: Dr. Joseph Maalouly, Department of Orthopaedic Surgery and spine surgery, Spine Ortho Clinic, Suite 10, 1st Floor, The Bays Hospital, Vale St, Mornington, VIC 3931, Australia. E-mail: josephmaalouly2@gmail.com

\begin{abstract}
How to cite this article: Choi J, Rhee I, Sakar M, Park I, Maalouly J. Single position lateral lumbar interbody fusion and pedicle screw fixation: preliminary experience and perioperative results. Mini-invasive Surg 2021;5:43.
\end{abstract}

https://dx.doi.org/10.20517/2574-1225.2021.73

Received: 3 Jun 2021 First Decision: 29 Jun 2021 Revised: 4 Jul 2021 Accepted: 27 Jul 2021 First online: 27 Jul 2021

Academic Editor: Yoshihisa Kotani Copy Editor: Xi-Jun Chen Production Editor: Xi-Jun Chen

\begin{abstract}
Aim: The purpose of this study was to review a single surgeon's preliminary experiences with minimally invasive single lateral position anterior-to-psoas lumbar interbody fusion with multiple techniques of percutaneous pedicle screws and present perioperative results and complication rates.
\end{abstract}

Methods: After obtaining Institutional Review Board approval, thirty-five consecutive patients undergoing, in 20182020, single position lateral interbody fusion with posterior fixation after obtaining written informed consent. Pedicle screw accuracy, screw-related complications, overall and segmental lumbar lordosis, intraoperative data, perioperative complications, and Visual Analog Pain Scale (VAS) at 6 months follow-up were collected.

Results: One hundred sixty-nine pedicle screws were placed in 35 patients with a 95.3\% accuracy rate. 6/7 breaches measured $<2 \mathrm{~mm}$. No complications or reoperations were performed in relation to screw malposition. Mean preoperative overall lumbar lordosis was $45.6^{\circ} \pm 12.5^{\circ}\left(\right.$ range, $\left.19^{\circ}-71^{\circ}\right)$, and $50.3^{\circ} \pm 9.6^{\circ}\left(\right.$ range, $\left.25^{\circ}-67^{\circ}\right)$ at 6 months follow up. Mean preoperative VAS scores were $7.3 \pm 1.2$ (range, 5-10) and $7.3 \pm 1.3$ (range, 5-10) for the back and leg, respectively and at 6 months follow up, $2.6 \pm 2.3$ (range, 0-7) and $2.6 \pm 2.2$ (range, 0-7) for the back and leg, respectively. The mean total operative time was $152.2 \pm 54.8 \mathrm{~min}$ (range, 80-320 min). 
Conclusion: Single lateral position antepsoas lumbar interbody fusion with bilateral percutaneous pedicle screws and rod fixation report comparable screw accuracy rates, operative times, and lordosis correction with the published literature. This modified technique eliminates the resources and time related to intraoperative prone repositioning and may lead to significant cost savings.

Keywords: Lumbar interbody fusion, extreme lateral interbody fusion, pedicle screw, computer-assisted navigation, minimally invasive surgery

\section{INTRODUCTION}

Non-specific back pain due to degenerative lumbar disorders significantly reduces patient function, increases pain scores, and impair quality of life $\mathrm{f}^{[1,2]}$. Lumbar interbody fusion (LIF) surgery has been widely used as a viable option in treating lower back pain and associated neurological disorders refractory to conservative treatment $t^{[3,4]}$. Several options for open and minimally invasive surgical LIF include posterior or transforaminal lumbar interbody fusion (P/TLIF) or anterior lumbar interbody fusion (ALIF) ${ }^{[5,6]}$.

Recently, a more minimally invasive, lateral lumbar interbody fusion (LLIF) is attracting attention with two main approaches; the transpsoas, direct LIF, and anterior-to-psoas, oblique LIF ${ }^{[7,8]}$. Although these LLIF approaches have not yet gained universal acceptance, early results show similar advantages to ALIF due to its large intervertebral spacer providing restoration of alignment and effective indirect neural decompression. The LLIF approaches also significantly mitigate the many approach-related visceral, vascular, and reproductive complications seen in $\operatorname{ALIF}^{[9-15]}$.

LLIF traditionally requires intraoperative patient repositioning from the lateral decubitus to the prone position to complete supplementary posterior instrumentation with bilateral pedicle screws ${ }^{[16]}$. Repositioning requires additional prepping, draping, and room positioning, which may significantly increase costs, operative time, risk of contamination, possible graft migration, and anaesthesia related complications ${ }^{[17-20]}$. Furthermore, the lateral position tends to be better tolerated by patients compared to prone surgery and avoids many of the major complications associated with the prone position, such as postoperative vision loss, cardiac arrest/complications, reduced pulmonary compliance, and nerve palsies $^{[21-23]}$.

Theoretical concerns regarding lateral position bilateral pedicle screw insertion have been raised, namely inadequate correction of lumbar lordosis as well as difficulty with pedicle screw placement ${ }^{[24-26]}$. However, several radiographic studies have reported unchanged lumbar lordosis between the prone and lateral positions after $\operatorname{LLIF}^{[27,28]}$.

The literature regarding single position LLIF with posterior fixation is increasing, but it has not been adopted universally yet ${ }^{[29]}$. The purpose of this study was to review a single surgeon's preliminary experiences with single lateral position anterior-to-psoas lumbar interbody fusion with different techniques of bilateral percutaneous pedicle screws and present perioperative results and complication rates.

\section{METHODS}

A retrospective review of collected data was performed on 35 consecutive patients who underwent singleposition antepsoas LIF with bilateral percutaneous pedicle screws and rod fixation at a single institution during October 2018 to February 2020. Informed consent was obtained from all patients prior to the procedure and once again confirmed at their 6-month follow-up appointment. After obtaining institutional 
review board (IRB) approval, we reviewed the patients' medical records, spinal radiographs, computer tomography (CT), and magnetic resonance imaging (MRI). Patient demographics, lumbar pathology, comorbidities, and the lists of surgical managements performed, including past, index, and subsequent operations, were recorded. Surgical details such as the operative technique, number of operative levels, total operative time, perioperative complications, reoperation, and length of hospital stay were noted.

Surgical indication was patients who presented with severe back and/or radiculopathy that was refractory to a trial of conservative treatment, including physical therapy, non-steroidal anti-inflammatory medication, narcotics, and steroid injections. Inclusion criteria were patients over the age of 18 undergoing single lateral decubitus position antepsoas lateral lumbar interbody fusion with bilateral percutaneous screws for any degenerative lumbar pathology [Figure 1]. Exclusion criteria included patients with inadequate preoperative imaging available for review and those undergoing combined procedures such as a direct posterior decompression or transforaminal lumbar interbody fusion. All operations were performed by a single surgeon (John Choi), and as such slight selection bias was present.

\section{Surgical technique}

Patient positioning

Patient is positioned in the lateral decubitus position with the left side up one-fourth the way from the surgeon on a flat Jackson table. The hip is positioned at the break of the operating table and gently flexed to relax the psoas muscle and femoral nerve. A pillow is placed between the knees, the taping of the lower pelvis and the uppermost hip and femur is performed to stabilise the spine and allow gentle traction of the pelvis. Anteroposterior fluoroscopy is used to ensure that the spine is not rotated, and lateral fluoroscopy is performed to ensure that the disc space is perpendicular to the floor. Care is then taken to further stabilise the patient in the lateral decubitus position with padding of the extremities and the chest, and the skin overlying the disc spaces are marked.

Optimal patient positioning is vital for single position LLIF; positioning too far from the table's edge can limit the surgeon's ability to drop their hand low enough to medialise the downside pedicle, whilst positioning too close to the table can cause interference with the lateral fluoroscopy. Similar to Blizzard et al. ${ }^{[17]}$, a location one-fourth the way across the bed from the surgeon was chosen ${ }^{[17]}$. Additionally, slightly rotating the table allowed the surgeon to more appropriately drop their hand and medialise the downside pedicle screw while also bringing the peritoneal sac further away from the spine and psoas and aiding in the anterior dissection.

\section{Antepsoas lumbar interbody fusion}

Modified surgical technique for the antepsoas lumbar interbody fusion described by Silvestre et al. ${ }^{[11]}$ was used in our study ${ }^{[11]}$. A $4 \mathrm{~cm}$ skin incision of the lateral abdomen, centred on the spinal segment and parallel to the external oblique muscle fibres, was made. Abdominal wall muscles were then dissected with a musclesplitting approach, and the retroperitoneal space was accessed by blunt dissection. The anatomical oblique lateral corridor was exposed by the anterior mobilisation of the peritoneal contents and careful retraction of the psoas muscle.

Radiolucent spine-mounted retractor systems with direct illumination were used to expose and visualise the intervertebral disc. Fluoroscopy was performed to confirm the proper spinal level and a discectomy centred on the anterior half of the disc space was then completed. Disc removal and contralateral annulus release with a cobb dissector provided the potential for placing a large implant resting on both lateral margins of the epiphyseal ring, and maximising endplate support. Endplates were prepared to expose the subchondral 

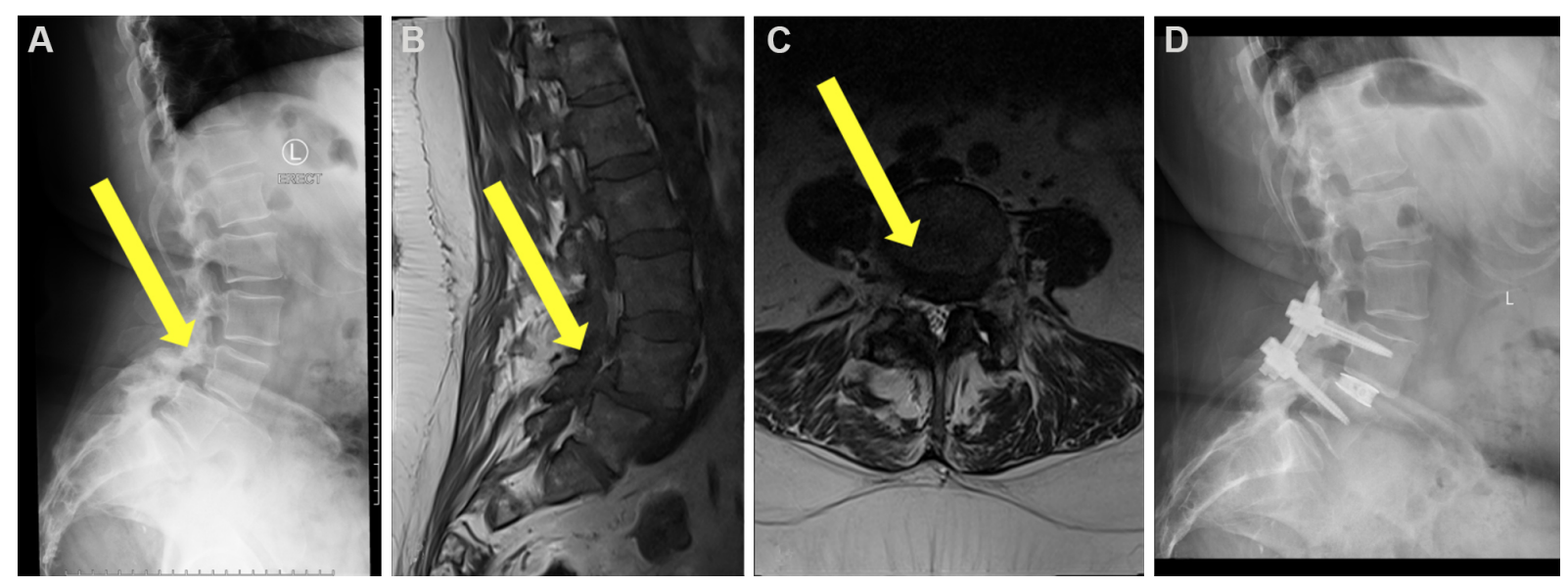

Figure 1. Patient 24. Treatment of degenerative spondylolisthesis of $L 4 / 5$. (A) Preoperative lateral radiograph, (B) preoperative midsagittal magnetic resonance imaging slice, (C) preoperative coronal slice at pathology, (D) postoperative lateral radiograph.

bone, and interbody cage was appropriately sized. Standard lateral cage was inserted across the disc space to gaining bilateral cortical endplate coverage.

Due to the mobility of the abdominal wall, up to three intervertebral discs could be approached using the same $4 \mathrm{~cm}$ incision by utilising the "sliding window" technique. However, in some cases with more than two levels, the surgeon split the deeper two muscles twice, having extended the external oblique split to access the disc space.

\section{Bilateral percutaneous pedicle screws}

After interbody cage placement, posterior bilateral pedicle screw fixation was performed by either fluoroscopy, CT navigation, or robot-assisted techniques, all of which have been previously described in the literature ${ }^{[17,30,31]}$. The method of pedicle screw placement was carefully planned preoperatively and agreed upon by the informed decision of the patient and surgeon's discretion.

For fluoroscopy-guided pedicle screws, anteroposterior (AP) radiographs were taken to mark the lateral borders of the pedicle, and a lateral view was shown to mark the centre of the pedicles. Percutaneous exposure was made by a small stab incision $2 \mathrm{~cm}$ lateral to the lateral border of each pedicle. Pedicle access needle was inserted by tactile feedback at the junction of the superior articular process and transverse process, and then cannulated by using alternating AP and lateral fluoroscopy. K-wires were then inserted and used to confirm the intact walls of the pedicle, and an appropriately sized pedicle screw was placed over the wires. Careful attention was given throughout this process to maintain medial angulation adequately.

For the CT-navigated system, pedicle screw trajectories were firstly planned preoperatively. Intraoperatively, a dynamic reference base and surveillance markers were placed, and an intraoperative CT was performed to obtain the image coordinate system. By utilising the navigation system, the skin over the pedicle screws was marked, and a small stab incises $2 \mathrm{~cm}$ lateral to the border of the pedicle was made. The junction between the transverse process and superior articular process was found by blunt dissection, and the pedicle was tapped and drilled under navigation guidance. Pedicle screws were then inserted using CT navigation with the previously planned trajectories. 
For patients opting for robot-assisted pedicle screw insertions, a 3rd generation floor mounted robot (ExcelsiusGPS, Globus Medical, Inc. Audubon, PA, USA) was utilised. Similar to the CT navigation system, a dynamic reference base and surveillance markers were placed, and the image coordinate system was obtained from a portable intraoperative CT. From there, pedicle screw trajectory planning was performed. A surgeon-controlled foot pedal was then used to activate and position the robot arm to the planned pedicle trajectory. Small stab incisions were used, and guide holes were created and tapped. Pedicle screws were then inserted by the surgeon under assistance from the robotic arm.

After the insertion of the pedicle screws, a rod was passed percutaneously and secured the pedicle screw head using torque-limiting locking caps. Intraoperative fluoroscopy was then utilised to verify the pedicle screw, interbody spacer, and rod position.

\section{Outcomes}

CT scans were routinely obtained 6 months postoperatively to assess fusion and hardware placement and integrity. Screw accuracy was evaluated using the technique seen by Spitz et al. ${ }^{[32]}$, where screw breaches were graded based upon the magnitude and direction of the breach; $\mathrm{A}=0-2 \mathrm{~mm}, \mathrm{~B}=2-4 \mathrm{~mm}, \mathrm{C} \geq 4 \mathrm{~mm}^{[32]}$. Lumbar lordosis (L1-S1) was obtained by preoperative and 6 months follow-up anteroposterior and lateral radiograph ${ }^{[33]}$. All radiographic outcome measures were reviewed by an independent orthopaedic fellow (Mehul Sakar).

Visual Analog Pain Scale (VAS) for the legs and/or back was recorded preoperatively and at 6 months follow-up.

\section{Statistics}

Data were presented as mean \pm SD (range). Statistical analysis included descriptive statistics, and two-tailed paired $t$-test or Mann-Whitney $U$ test (if non-normally distributed) was used. A $P$ value of $<0.05$ was defined as statistically significant. Data distributions were evaluated using the Shapiro-Wilks test.

\section{RESULTS}

Patient characteristics and results are presented in Table 1. Thirty-five patients (17 males and 18 females) with a mean age at surgery of 69 years (46-87 years) were included in this study. All patients were followed up for a minimum of 6 months after surgery. The mean body mass index (BMI) was 31.9 (22.0-50.9), and $26 \%$ of the cohort had a history of smoking whilst $17 \%$ had diabetes. Most of the patients had no previous lumbar spine surgery (83\%), and those that did had either a laminectomy (9\%), microdiscectomy (5\%), or PLIF (3\%).

Surgical data are presented in [Table 2]. The primary indication for surgery in our cohort included spondylolisthesis (46\%), degenerative disc disease (44\%), stenosis (5\%), and scoliosis (5\%). A total of 51 lumbar intervertebral disc levels were operated on, with 23 patients undergoing single-level surgery, 8 undergoing two-level fusions, and 4 undergoing three-level fusions. The most common spinal level treated was L4/5 (22 patients), followed by L5/S1 (21 patients), L3/4 (15 patients), and L2/3 (2 patients). The mean total operative time was $152.2 \pm 54.8 \mathrm{~min}(80-320 \mathrm{~min})$, and the mean length of hospitalization was $5.3 \pm 1.7$ days (3-9 days).

A total of 169 pedicle screws were placed; 72 screws using fluoroscopy, 10 screws with CT navigation, and 87 with robot assistance. Different techniques were used for pedicle screws placement in part due to the surgeon transitioning from navigation use to robot-assisted technique. Also, fluoroscopic guided 
Table 1. Patient information

\begin{tabular}{|c|c|c|c|c|c|c|c|c|c|c|c|c|c|c|c|c|c|c|c|}
\hline & \multirow{3}{*}{$\begin{array}{l}\text { Age } \\
\text { (years) } \\
\text { /Sex }\end{array}$} & \multirow{3}{*}{ BMI } & \multirow{3}{*}{ Pathology } & \multirow{3}{*}{$\begin{array}{l}\text { Operative } \\
\text { levels }^{\star}\end{array}$} & \multirow{3}{*}{$\begin{array}{l}\text { BPS } \\
\text { technique }\end{array}$} & \multirow{3}{*}{$\begin{array}{l}\text { OR time } \\
\text { (min) }\end{array}$} & \multirow{3}{*}{$\begin{array}{l}\text { LOS } \\
\text { (days) }\end{array}$} & \multicolumn{5}{|c|}{$\begin{array}{c}\text { Screw } \\
\text { accuracy }\end{array}$} & \multicolumn{2}{|c|}{$\begin{array}{c}\text { Overall } \\
\text { LL }\end{array}$} & \multicolumn{2}{|c|}{$\begin{array}{c}\text { Segmental } \\
\text { LL }\end{array}$} & \multirow{3}{*}{$\begin{array}{l}\text { Pre VAS } \\
\text { (back/leg) }\end{array}$} & \multirow{3}{*}{$\begin{array}{l}\text { Postop VAS } \\
\text { (back/leg) }\end{array}$} & \multirow{3}{*}{ Comment } \\
\hline & & & & & & & & \multirow{2}{*}{$\mathbf{N}$} & $B$ & U & & D & Dro & $5 / 1$ & Dro & $5 / 1$ & & & \\
\hline & & & & & & & & & & M L & $\mathbf{M}$ & $\mathbf{L}$ & Pre & $\mathrm{r} / \mathrm{J}$ & Pre & $r / 0$ & & & \\
\hline 1 & $64 / F$ & 40.2 & SL & $\mathrm{L} 4 / 5$ & Fluoro & 135 & 5 & 4 & & & & & 44 & 50 & 19 & 22 & $6 / 6$ & & \\
\hline 2 & $71 / \mathrm{F}$ & 38.3 & $\mathrm{SL}, \mathrm{DDD}$ & L3-S1 & Fluoro & 272 & 9 & 8 & & & & & 39 & 54 & 31 & 40 & $7 / 9$ & $3 / 4$ & \\
\hline 3 & $60 / F$ & 37.5 & DDD & $\llcorner 4 / 5$ & Fluoro & 100 & 8 & 4 & & & & & 29 & 44 & 16 & 20 & $8 / 8$ & $2 / 2$ & \\
\hline 4 & $84 / \mathrm{M}$ & 26.7 & DDD & L3-L5 & Fluoro & 172 & 6 & 6 & & & & & 50 & 47 & 32 & 32 & $6 / 6$ & $4 / 0$ & $\begin{array}{l}\text { L5 fracture, recurrent } \\
\text { symptoms, reoperation }\end{array}$ \\
\hline 5 & $65 / F$ & 28.5 & $S L$ & $\mathrm{~L} 4 / 5$ & Fluoro & 152 & 3 & 4 & & & & & 52 & 55 & 20 & 20 & $8 / 8$ & $4 / 4$ & \\
\hline 6 & $85 / \mathrm{M}$ & 25.8 & $\mathrm{SL}, \mathrm{ST}$ & $\llcorner 4 / 5$ & Fluoro & 120 & 5 & 4 & & & & & 46 & 57 & 21 & 23 & $5 / 5$ & $0 / 0$ & \\
\hline 7 & $76 / M$ & 35.2 & SL & L5/S1 & Nav & 164 & 5 & 4 & & & & & 55 & 59 & 20 & 24 & $8 / 8$ & $6 / 6$ & Partial cage protrusion \\
\hline 8 & $73 / F$ & 25.0 & $\begin{array}{l}\mathrm{SL}, \mathrm{DDD} \\
\mathrm{ST}\end{array}$ & L3-L5 & Fluoro & 129 & 5 & 6 & & & & & 52 & 55 & 31 & 33 & $6 / 6$ & $5 / 5$ & Transient neuralgia \\
\hline 9 & $76 / M$ & 29.4 & SL & $\llcorner 4 / 5$ & Fluoro & 134 & 7 & 4 & & & & & 43 & 40 & -8 & 5 & $-/ 5$ & $-/ 0$ & Delirium, pneumonia \\
\hline 10 & $87 / \mathrm{F}$ & 33.7 & DDD & L4-S1 & Nav & 115 & 6 & 6 & & & & & 40 & 47 & 13 & 17 & $7 / 7$ & $5 / 5$ & $\begin{array}{l}\text { Persistent symptoms, R/O of } \\
\text { cage }\end{array}$ \\
\hline 11 & $77 / M$ & 22.0 & $\mathrm{SL}, \mathrm{DDD}$ & $L 5 / S 1$ & Fluoro & 130 & 6 & 4 & & & & & 40 & 57 & 11 & 25 & $6 / 6$ & b & Transient neuralgia \\
\hline 12 & $61 / M$ & 30.0 & $\mathrm{DDD}, \mathrm{SC}$ & $\llcorner 4 / 5$ & Fluoro & 154 & 3 & 4 & & & & & 45 & 50 & 16 & 18 & $8 / 8$ & $3 / 1$ & Transient neuralgia \\
\hline 13 & $72 / \mathrm{F}$ & 25.1 & SL & $\mathrm{L} 4 / 5$ & $\mathrm{R}$ & 158 & 6 & 4 & & & & & 56 & 56 & 20 & 20 & $-/ 8$ & $-/ 4$ & $\begin{array}{l}\text { Persistent symptoms, } \\
\text { microdiscectomy (L4/5), new } \\
\text { onset AF }\end{array}$ \\
\hline 14 & $79 / F$ & 33.1 & $\begin{array}{l}\text { SL, DDD, } \\
\text { SC }\end{array}$ & $\mathrm{L} 5 / \mathrm{S} 1$ & $\mathrm{R}$ & 172 & 3 & 4 & & & & & 56 & 56 & 25 & 29 & $8 / 8$ & $2 / 2$ & Transient neuralgia \\
\hline 15 & $62 / \mathrm{M}$ & 33.3 & DDD & L3-S1 & $\mathrm{R}$ & 320 & 5 & 8 & & & & & 30 & 46 & 30 & 38 & $6 / 6$ & $6 / 3$ & \\
\hline 16 & $60 / M$ & 38.0 & SC & $\mathrm{L} 2 / 3$ & Fluoro & 135 & 3 & 4 & & & & & 28 & 40 & 6 & 6 & $8 / 8$ & $2 / 2$ & \\
\hline 17 & $66 / M$ & 30.1 & SL & $\llcorner 4 / 5$ & $\mathrm{R}$ & 95 & 4 & 4 & & & & & 59 & 59 & 25 & 36 & $8 / 8$ & $0 / 0$ & \\
\hline 18 & $72 / \mathrm{M}$ & 29.9 & DDD & $\mathrm{L} 3 / 4$ & $\mathrm{R}$ & 101 & 4 & 4 & & & & & 50 & 50 & 9 & 11 & $6 / 6$ & $0 / 0$ & \\
\hline 19 & $79 / M$ & 31.8 & DDD & L3-L5 & $\mathrm{R}$ & 195 & 6 & 6 & & & & & 22 & 25 & 14 & 14 & $7 / 7$ & $4 / 4$ & \\
\hline 20 & $69 / F$ & 40.0 & DDD & L4-S1 & $\mathrm{R}$ & 297 & 6 & 4 & 1 & & & 1 & 35 & 45 & 25 & 36 & $8 / 8$ & $5 / 5$ & Transient neuralgia - left leg \\
\hline 21 & $70 / \mathrm{M}$ & 22.2 & ST & $\mathrm{L} 3 / 4$ & Fluoro & 80 & 4 & 4 & & & & & 46 & 46 & 12 & 14 & $8 / 8$ & $2 / 2$ & \\
\hline 22 & $72 / \mathrm{M}$ & 28.7 & DDD & $\mathrm{L} 5 / \mathrm{S} 1$ & Fluoro & 175 & 3 & 4 & & & & & 47 & 60 & 13 & 34 & $6 / 6$ & $0 / 0$ & \\
\hline 23 & $76 / F$ & 30.2 & DDD & $\mathrm{L} 2 / 3$ & $\mathrm{R}$ & 135 & 9 & 4 & & & & & 22 & 25 & 1 & 2 & $10 / 10$ & $1 / 1$ & $\begin{array}{l}\text { New onset of back pain, } \\
\text { microdiscectomy (L4/5, } \\
\text { L5/S1) }\end{array}$ \\
\hline 24 & $61 / F$ & 34.9 & $S L$ & $\mathrm{~L} 4 / 5$ & $\mathrm{R}$ & 130 & 6 & 4 & & & & & 60 & 67 & 24 & 32 & $6 / 6$ & $1 / 1$ & \\
\hline
\end{tabular}




\begin{tabular}{|c|c|c|c|c|c|c|c|c|c|c|c|c|c|c|c|c|c|c|}
\hline 25 & $77 / M$ & 34.9 & DDD & $\mathrm{L} 3 / 4$ & Fluoro & 95 & 6 & 4 & & & & 63 & 63 & 12 & 20 & $10 / 10$ & $1 / 1$ & Transient neuralgia \\
\hline 26 & $66 / F$ & 36.2 & $\mathrm{DDD}, \mathrm{ST}$ & L3-S1 & $\mathrm{R}$ & 170 & 9 & 5 & 3 & 1 & 2 & 42 & 44 & 40 & 41 & $8 / 8$ & $7 / 7$ & $\begin{array}{l}\text { Postoperative fall, recurrent } \\
\text { symptoms, plan for reoperation }\end{array}$ \\
\hline 27 & $72 / M$ & 29.7 & DDD & L3-S1 & $R$ & 230 & 5 & 6 & 11 & 1 & 2 & 59 & 55 & 50 & 48 & $6 / 6$ & $2 / 2$ & $\begin{array}{l}\text { Persistent left leg/back pain, } \\
\text { SIJ fusion }\end{array}$ \\
\hline 28 & $75 / M$ & 27.7 & DDD & $\mathrm{L} 3 / 4$ & Fluoro & 105 & 7 & 4 & & & & 53 & 59 & 12 & 16 & $8 / 8$ & $1 / 0$ & Urosepsis, delirium \\
\hline 29 & $60 / F$ & 27.5 & DDD & L3-L5 & Fluoro, R & 177 & 4 & 5 & 1 & & 1 & 19 & 33 & 0.75 & 12 & $5 / 5$ & $0 / 1$ & \\
\hline 30 & $46 / F$ & 38.7 & $S L$ & $L 3 / 4$ & Fluoro & 118 & 5 & 4 & & & & 54 & 54 & 10 & 10 & $8 /-$ & $2 /-$ & Wound infection \\
\hline 31 & $63 / F$ & 25.9 & SC & L3-L5 & Fluoro, R & 130 & 4 & 6 & & & & 57 & 57 & 19 & 28 & $8 / 8$ & $0 / 4$ & \\
\hline 32 & $59 / M$ & 29.4 & ST & $\mathrm{L} 3 / 4$ & $R$ & 145 & 4 & 4 & & & & 38 & 46 & 7 & 9 & $8 / 8$ & & \\
\hline 33 & $62 / F$ & 28.7 & $S L$ & $\mathrm{~L} 5 / \mathrm{S} 1$ & $R$ & 110 & 4 & 4 & & & & 71 & 57 & 35 & 22 & $8 / 8$ & $0 / 0$ & \\
\hline 34 & $61 / \mathrm{F}$ & 50.9 & $S L$ & $\llcorner 4 / 5$ & $R$ & 147 & 7 & 4 & & & & 51 & 24 & 51 & 26 & $9 / 9$ & $7 / 7$ & $\begin{array}{l}\text { Respiratory distress, prolonged } \\
\text { ICU stay }\end{array}$ \\
\hline 35 & $74 / F$ & 28.7 & SL, ST & L4/5 & $\mathrm{R}$ & 130 & 6 & 4 & & & & 49 & 56 & 10 & 16 & $7 / 7$ & $5 / 5$ & \\
\hline
\end{tabular}

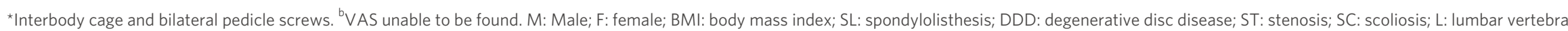
body; S: sacrum; BPS: bilateral pedicle screw; Fluoro: fluoroscopy; Nav: CT navigation; R: robot assisted; OR: operating room; LOS: length of stay; NB: no breach; A: Spitz grade A breach (<2 mm); B: Spitz grade B breach (2-4 mm); U: upside screw; D: downside screw; M: medial breach; L: lateral breach; Pre: preoperative; F/U: follow-up; Postop: postoperative.

percutaneous pedicle screw placement was used in two patients due to robot malfunction and in the other cases due to the surgeon's preference. It is important to note that all the techniques can be readily used depending on the availability of the equipment. Six months follow-up CT scans were obtained from 35 (100\%) patients. $95.3 \%$ of screws were successfully placed with no breaches, and 7 total screw breaches were identified (4.7\%); 6 were graded A breaches (< $2 \mathrm{~mm}), 1$ grade B $(2-4 \mathrm{~mm})$ [Figure 2], and 0 grade C $(>4 \mathrm{~mm})$ breaches; it showed no statistically significant difference with $P=0.14$. Of the 7 breached screws, 6 were downside/right-hand side screws, all with lateral breaches, and a medial breach was observed for the 1 upside/left-hand side screw [Table 3]. Based on the surgeon's discretion, 2/87 robot-assisted screws were manually repositioned, both of which were later identified as breaches. In our series, all breach screws were placed with robot assistance, and a clear trend of lateral breach laterality is seen in the downside screws. In our cohort, no complications were reported due to screw placement, and revision surgery was not performed due to screw malposition.

Overall lumbar lordosis improved significantly from $45.6^{\circ} \pm 12.5^{\circ}\left(19^{\circ}-71^{\circ}\right)$ preoperatively to $50.3^{\circ} \pm 9.6^{\circ}\left(25^{\circ}-67^{\circ}\right)$ at 6 months follow up $(P<0.001)$. Similarly, segmental lumbar lordosis significantly increased for one-level and two-level lumbar fusions, from $14^{\circ} \pm 9^{\circ}\left(-8^{\circ}-35^{\circ}\right)$ to $19^{\circ} \pm 9^{\circ}\left(2^{\circ}-36^{\circ}\right)(P<0.004)$ and $19^{\circ} \pm$ $11^{\circ}\left(0.5^{\circ}-32^{\circ}\right)$ to $25^{\circ} \pm 10^{\circ}\left(12^{\circ}-36^{\circ}\right)(P=0.03)$, respectively at 6 months follow up. For three-level fusions, segmental lordosis did not significantly change $(P=$ $0.23)$ [Table 4]. 
Table 2. Surgical data

\begin{tabular}{ll}
\hline Parameter & Overall \\
\hline Primary pathology $n(\%)$ & \\
Spondylolisthesis & $16(46 \%)$ \\
Degenerative disc disease & $15(44 \%)$ \\
Scoliosis & $2(5 \%)$ \\
Stenosis & $2(5 \%)$ \\
Number of levels treated $n$ (\%) & \\
1 & $23(67 \%)$ \\
2 & $8(22 \%)$ \\
3 & $4(11 \%)$ \\
Operative time (min), mean \pm SD (range) & $152.2 \pm 54.8(80-320)$ \\
Hospital stay (days), mean \pm SD (range) & $5.3 \pm 1.7(3-9)$ \\
Future operations & \\
Microdiscectomy & 2 \\
Cage removal & 1 \\
Sacroiliac joint fusion & 1 \\
\hline
\end{tabular}

Table 3. Screw accuracy

\begin{tabular}{|c|c|c|c|c|c|}
\hline \multirow{2}{*}{ Breach grade } & \multirow{2}{*}{ No. of screws } & \multicolumn{2}{|c|}{ Upside pedicle } & \multicolumn{2}{|c|}{ Downside pedicle } \\
\hline & & Medial & Lateral & Medial & Lateral \\
\hline No breach & $162(95.3 \%)$ & & & & \\
\hline Grade A & $6(4.7 \%)$ & 1 & & & 5 \\
\hline Grade B & $1(0 \%)$ & & & & 1 \\
\hline Grade C & $0(0 \%)$ & & & & \\
\hline
\end{tabular}

$P=0.14$, represent the comparison between upside and downside pedicle screws.

Table 4. Lumbar lordosis

\begin{tabular}{lllll}
\hline & Overall LL & One level segmental LL & Two level segmental LL & Three level segmental LL \\
\hline Preoperative & $45.6^{\circ} \pm 12.5^{\circ}$ & $14^{\circ} \pm 9^{\circ}$ & $19^{\circ} \pm 11^{\circ}$ & $38^{\circ} \pm 9^{\circ}$ \\
Postoperative & $50.3^{\circ} \pm 9.6^{\circ}$ & $19^{\circ} \pm 9^{\circ}$ & $25^{\circ} \pm 10^{\circ}$ & $42^{\circ} \pm 4^{\circ}$ \\
$P$ value & $<0.001$ & $<0.004$ & $<0.03$ & $=0.23$ \\
\hline
\end{tabular}

*Two tailed paired t-test. LL: Lumbar lordosis.

Mean VAS scores for back and leg significantly improved after the index operation, from $7.3 \pm 1.2(5-10)$ to $2.6 \pm 2.3(0-7)(P<0.001)$ and $7.3 \pm 1.3(5-10)$ to $2.6 \pm 2.2(0-7)(P<0.001)$, respectively at 6 months follow up. Unfortunately, 3 postoperative patients reported VAS scores were unable to be found.

Postoperative pain unrelated to pedicle screw placement included persistent symptoms in 3 patients. Patient 10 experienced complete resolution of back pain but continued to suffer significant leg symptoms postoperatively due to an unexpanded hyperlordotic cage. This cage was subsequently removed. Patient 13 experienced no improvement in back or leg pain and underwent a microdiscectomy and posterior decompression during the follow-up period. Patient 27 reported left leg and back pain 3 months postoperatively, and a sacroiliac joint fusion was conducted. Patients' complications are summarized in Table 1. 

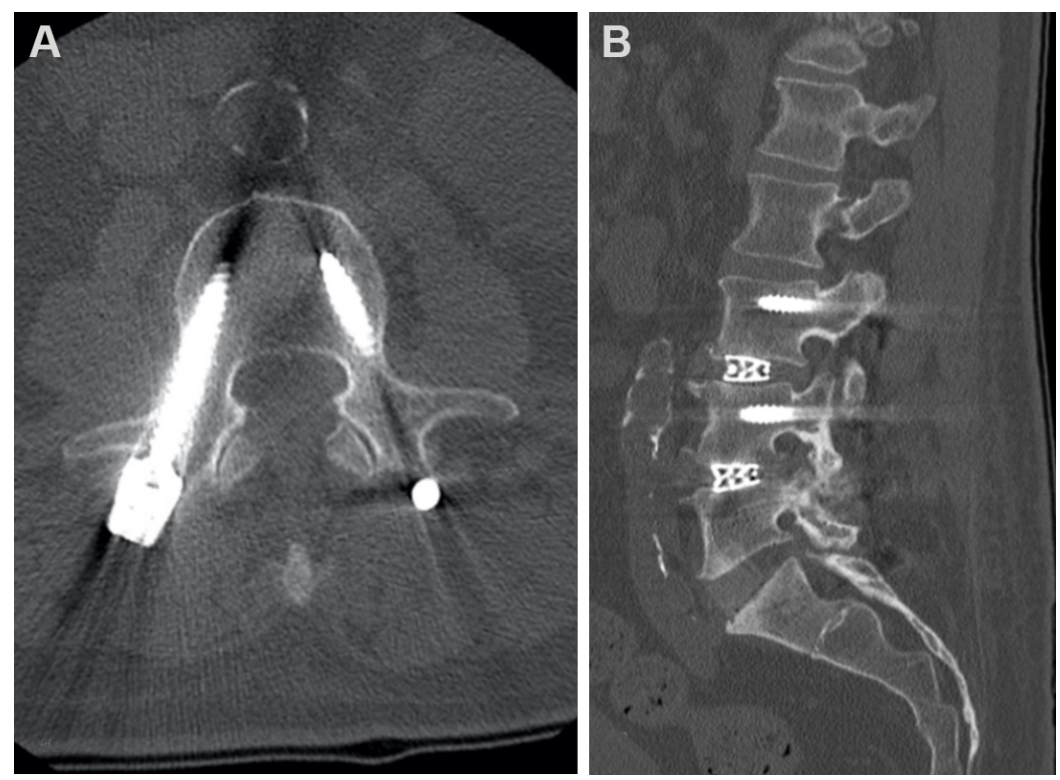

Figure 2. Patient 27. Grade B (2-4 mm) of right hand downside L3 pedicle screw. (A) Postoperative coronal computerized tomography slice, (B) postoperative sagittal computerized tomography slice.

Other complications included delays of the transfer due to bed shortages at rehabilitation centres (6), pneumonia (1), respiratory distress (1), prolonged intensive care unit stay (1), delirium (2), new-onset atrial fibrillation (1), wound infection (1), urinary tract infection (1) and urosepsis (1).

\section{DISCUSSION}

Providing high-quality, value-based treatments is essential for the patient's benefit and sustainability of healthcare systems. Alternative forms of surgical techniques with low operative times and procedural morbidities decrease hospital costs, shorten recovery times and improve patient experiences ${ }^{[34-36]}$. Traditionally, the prone position is utilized by spine surgeons to gain access to the spinal column ${ }^{[21-23]}$. Recently, there has been increasing interest in completing LLIF in the single lateral position, and reports of reduced operative times and consequent cost reductions have been made ${ }^{[17,18,3]}$. This study builds on the previous work of Blizzard et al. ${ }^{[17]}$ and Ziino et al. ${ }^{[18]}$, and found favourable outcomes for primary endpoints including, screw accuracy, complication rates, surgical efficiency, and lordosis correction.

Pedicle screw misplacement rates for conventional prone position techniques vary greatly in the literature, ranging from $5 \%$ to $41 \%^{[38-42]}$. It represents the significant heterogeneity in the radiographic modalities and grading schemes used in studies to assess screw accuracy. Breach rates of $1.5 \%$ to $14.3 \%$ were found when the literature was limited to studies investigating screw accuracy rates with postoperative CT imaging ${ }^{[17]}$. Currently, some papers have assessed pedicle screw accuracy in single position LLIF, and Blizzard et al. ${ }^{[17]}$ reported an overall breach rate of $5.1 \%$, with $1.2 \%$ of screws between $2-4 \mathrm{~mm}$, whilst Sellin et al.$^{[30]}$, reported a $14 \%(2 / 14)$ overall breach rate in their 4 patient case series. Although there is no comparison cohort in the current study, the $4.7 \%$ overall breach rate and $0.7 \%$ grade $B(2-4 \mathrm{~mm})$ breach rate is consistent with the published literature. Moreover, the surgeon used the different techniques available, including robots, navigation, and fluoroscopic guided percutaneous pedicle screws. It can be helpful as robots and navigation are unable to use in every operating theatre in the world. 
Theoretical concerns regarding the medialization of downside pedicle screws during single position LLIF with posterior fixation have been raised. In this study, 6/7 breaches were identified on the downside screw with lateral laterality, which contrasts the lack of clear trends seen by Blizzard et al. ${ }^{[17]}$. Comparatively, Hiyama et al ${ }^{[43]}$ found that all breaches occurred on the lateral side. These results may validate the concerns of the surgeon's potential inability to drop their hands low enough for lateral position screw insertion. However, it must be noted that all breaches in this study occurred with the robot-assisted technique, and no breaches were found for the navigation or fluoroscopy-guided pedicle screw. It indicates that accurate downside screw placements with adequate medialisation can be established in the lateral position. This discrepancy between techniques can possibly be explained by the live intraoperative assessment and corrections that are made during fluoroscopic screw insertion. It could also be due to the movement of the dynamic reference base of the robot. Furthermore, the surgeon's familiarity with the prone fluoroscopic percutaneous pedicle screw technique may allow them to readily adapt the technique for the lateral position, similar to Blizzard et al. ${ }^{[17]}$, we did not appreciate a significant learning curve for the technique.

Huntsman et al. ${ }^{[31]}$ reported on the feasibility of single position robot-assisted pedicle insertion, although all the breaches of our study were associated with the robot, only $8 \%$ of robot-assisted screws were breach, with $1 \%$ of the breaches being greater than $2 \mathrm{~mm}$. These results remain comparable with the literature as breach rates of $3 \mathrm{~mm}$ or greater, ranged from $3.7 \%$ to $9.7 \%$ for fluoroscopic prone position pedicle screw insertions ${ }^{[17]}$. Similar to the fluoroscopic technique, there was no apparent learning curve associated with the robot-assisted technique, and pedicle screw placement is controlled and performed by the surgeon's discretion and guidance. Regardless of the technique utilized for single lateral position pedicle screw insertion after LLIF, our pedicle screw accuracy rates are consistent with the published literature.

Due to inconsistent criterion amongst surgeons, screw-related complication and reoperation rates are difficult to interpret amongst the published literature. Misplaced pedicle screws may result in significant injury to the nerve roots, spinal cord, vasculature, viscera, or cardiopulmonary system, all of which are potential threats to limb and life ${ }^{[42-45]}$. However, despite neural structures lying within $2 \mathrm{~mm}$ of the pedicle, complications are shown to be associated with breaches of $4 \mathrm{~mm}$ or more ${ }^{[46]}$. In the current study, we adopted a low threshold for reoperation, monitoring for new or persistent perioperative radiculopathies correlated with the pedicle screw vertebral level. No screws breaches greater than $4 \mathrm{~mm}$ were identified, and in line with the literature, 0 screw malposition-related complications were found, and consequently, no revision surgeries were performed ${ }^{[17,31,47]}$.

The current study exclusively investigating single-lateral-position multilevel antepsoas LLIF with posterior fixation, and a mean operative time of $152 \mathrm{~min}$ was found. These results align with other multilevel single position studies. Ziino et al. ${ }^{[18]}$ reported an operative time of 149.2 min whilst Huntsman et al. ${ }^{\left[{ }^{[1]}\right.}$ noted an operative time of $155.7 \mathrm{~min}$. Additionally, in Ziino et al. ${ }^{[18]}$ 's comparative study, the operative time of the dual position procedure was $44 \mathrm{~min}$ longer than the single position counterpart. A time saving of $44 \mathrm{~min}$ is substantial, and the majority of this time is likely from patient wound closure, re-positioning, re-prepping, and re-draping. A recent multicentre cohort review found that longer operative times are associated with a step-wise increase in overall, medical, and surgical complications rates ${ }^{[48]}$. Furthermore, the reduced operative time for single position LLIF may significantly reduce operative costs, with some papers suggesting a potential $\$ 3154$ saving per case ${ }^{[17,49]}$. Therefore, we suggest that spine surgeons who frequently perform lateral surgery consider the implementation of single position surgery.

Sagittal alignment is well-documented as the most critical and reliable radiographic predictor for patients' quality of life, and imbalances exacerbate patient-reported pain, function, and self-image ${ }^{[5,55]}$. Supporters of 
dual position surgery often argue that optimum restoration of lordosis is only obtained with the prone position $^{[25,52,53]}$. However, recently radiographic studies reported no additional lordosis correction from lateral-to-prone repositioning after the insertion of an interbody cage ${ }^{[27,28]}$. In the present study, overall, onelevel and two-level lumbar lordosis significantly improved by a mean of $4.7^{\circ}, 5^{\circ}$, and $6^{\circ}$, respectively. These results are consistent with recent systematic reviews investigating lordosis correction of LLIF with prone repositioning ${ }^{[54-56]}$. Furthermore, comparative studies have shown no significant difference in lordosis correction between the single lateral position LIF and lateral-to-prone repositioned techniques ${ }^{[1,5,5]}$. It suggests that adequate lordosis restoration can be achieved in the single lateral decubitus position, with no additional advantage from repositioning.

This study has several limitations. First, although this study has known limitations and biases relating to a retrospective, single-cohort study design, the results were consistent with the findings in the literature. Second, multiple pedicle screw insertion techniques were included in this study. However, the purpose of this study was to describe a surgeon's preliminary experience with single position LLIF with bilateral pedicle screw fixation and report on the short-term outcomes and complications of this modified technique. Future studies should compare the three current pedicle screw techniques of fluoroscopy, CT navigation, and robot assistance, especially investigating operative times, radiation times, and doses. Third, the surgeon performed his first cases with this particular robot which has its learning curve.

In conclusion, we presented in this study a surgeon's preliminary experience with a single position, multilevel antepsoas LIF with bilateral percutaneous pedicle screws and rod fixation and report comparable screw accuracy, overall complication rates, operative times, and lordosis correction with the published literature. This modified technique eliminates the resources and time related to intraoperative prone repositioning and may lead to significant cost savings. It can be done with fluoroscopy guidance, navigation, or robot.

\section{DECLARATIONS}

\section{Authors' contributions}

Supervisor of the research project, patient recruitment, writing and editing of the manuscript, main surgeon: Choi J

Writing and editing of the manuscript, data collection, data analysis: Rhee I

Writing and editing of the manuscript, data analysis: Sakar M

Writing of the manuscript, data collection: Park I

Writing and editing of the manuscript, data collection. data analysis, corresponding author: Maalouly J

\section{Availability of data and materials}

Available upon request.

\section{Financial support and sponsorship}

None.

\section{Conflicts of interest}

All authors declared that there are no conflicts of interest.

\section{Ethical approval and consent to participate}

Written informed consent, and IRB approval obtained. 


\section{Consent for publication}

Written informed consent.

\section{Copyright}

(c) The Author(s) 2021.

\section{REFERENCES}

1. Resnick DK, Choudhri TF, Dailey AT, et al; American Association of Neurological Surgeons/Congress of Neurological Surgeons. Guidelines for the performance of fusion procedures for degenerative disease of the lumbar spine. Part 8: lumbar fusion for disc herniation and radiculopathy. J Neurosurg Spine 2005;2:673-8. DOI PubMed

2. Kamper SJ, Apeldoorn AT, Chiarotto A, et al. Multidisciplinary biopsychosocial rehabilitation for chronic low back pain: Cochrane systematic review and meta-analysis. BMJ 2015;350:h444. DOI PubMed PMC

3. Takahashi K, Kitahara H, Yamagata M, et al. Long-term results of anterior interbody fusion for treatment of degenerative spondylolisthesis. Spine (Phila Pa 1976) 1990;15:1211-5. DOI PubMed

4. Castellvi AE, Nienke TW, Marulanda GA, Murtagh RD, Santoni BG. Indirect decompression of lumbar stenosis with transpsoas interbody cages and percutaneous posterior instrumentation. Clin Orthop Relat Res 2014;472:1784-91. DOI PubMed PMC

5. Mobbs RJ, Phan K, Malham G, Seex K, Rao PJ. Lumbar interbody fusion: techniques, indications and comparison of interbody fusion options including PLIF, TLIF, MI-TLIF, OLIF/ATP, LLIF and ALIF. J Spine Surg 2015;1:2-18. DOI PubMed PMC

6. Azar F, Canale ST, Beaty JH. Campbell's operative orthopaedics. 13th ed. Amsterdam: Elsevier; 2016. DOI

7. Ozgur BM, Aryan HE, Pimenta L, Taylor WR. Extreme lateral interbody fusion (XLIF): a novel surgical technique for anterior lumbar interbody fusion. Spine J 2006;6:435-43. DOI PubMed

8. Mayer HM. A new microsurgical technique for minimally invasive anterior lumbar interbody fusion. Spine (Phila Pa 1976) 1997;22:691-9; discussion 700. DOI PubMed

9. Cappuccino A, Cornwall GB, Turner AW, et al. Biomechanical analysis and review of lateral lumbar fusion constructs. Spine (Phila Pa 1976) 2010;35:S361-7. DOI PubMed

10. McGowan JE, Kanter AS. Lateral approaches for the surgical treatment of lumbar spondylolisthesis. Neurosurg Clin N Am 2019;30:313-22. DOI PubMed

11. Silvestre C, Mac-Thiong JM, Hilmi R, Roussouly P. Complications and morbidities of mini-open anterior retroperitoneal lumbar interbody fusion: oblique lumbar interbody fusion in 179 patients. Asian Spine J 2012;6:89-97. DOI PubMed PMC

12. Kaiser MG, Haid RW Jr, Subach BR, Miller JS, Smith CD, Rodts GE Jr. Comparison of the mini-open versus laparoscopic approach for anterior lumbar interbody fusion: a retrospective review. Neurosurgery 2002;51:97-103; discussion 103-5. DOI PubMed

13. Saraph V, Lerch C, Walochnik N, Bach CM, Krismer M, Wimmer C. Comparison of conventional versus minimally invasive extraperitoneal approach for anterior lumbar interbody fusion. Eur Spine J 2004;13:425-31. DOI PubMed PMC

14. Woods KR, Billys JB, Hynes RA. Technical description of oblique lateral interbody fusion at L1-L5 (OLIF25) and at L5-S1 (OLIF51) and evaluation of complication and fusion rates. Spine J 2017;17:545-53. DOI PubMed

15. Abe K, Orita S, Mannoji C, et al. Perioperative complications in 155 patients who underwent oblique lateral interbody fusion surgery: perspectives and indications from a retrospective, multicenter survey. Spine (Phila Pa 1976) 2017;42:55-62. DOI PubMed

16. Xu DS, Walker CT, Godzik J, Turner JD, Smith W, Uribe JS. Minimally invasive anterior, lateral, and oblique lumbar interbody fusion: a literature review. Ann Transl Med 2018;6:104. DOI PubMed PMC

17. Blizzard DJ, Thomas JA. MIS single-position lateral and oblique lateral lumbar interbody fusion and bilateral pedicle screw fixation: feasibility and perioperative results. Spine (Phila Pa 1976) 2018;43:440-6. DOI PubMed

18. Ziino C, Konopka JA, Ajiboye RM, Ledesma JB, Koltsov JCB, Cheng I. Single position versus lateral-then-prone positioning for lateral interbody fusion and pedicle screw fixation. J Spine Surg 2018;4:717-24. DOI PubMed PMC

19. Rhee JW, Petteys RJ, Anaizi AN, Sandhu FA, Voyadzis JM. Prospective evaluation of 1-year outcomes in single-level percutaneous lumbar transfacet screw fixation in the lateral decubitus position following lateral transpsoas interbody fusion. Eur Spine $J$ 2015;24:2546-54. DOI PubMed

20. Baum GR, Lin JD, Morr S, et al. Minimally invasive approach to the lumbosacral junction with a single position, $360^{\circ}$ fusion. $J$ Spine Surg 2019;5:S68-73. DOI PubMed PMC

21. Shriver MF, Zeer V, Alentado VJ, Mroz TE, Benzel EC, Steinmetz MP. Lumbar spine surgery positioning complications: a systematic review. Neurosurg Focus 2015;39:E16. DOI PubMed

22. DePasse JM, Palumbo MA, Haque M, Eberson CP, Daniels AH. Complications associated with prone positioning in elective spinal surgery. World J Orthop 2015;6:351-9. DOI PubMed PMC

23. Kwee MM, Ho YH, Rozen WM. The prone position during surgery and its complications: a systematic review and evidence-based guidelines. Int Surg 2015;100:292-303. DOI PubMed PMC

24. Harimaya K, Lenke LG, Mishiro T, Bridwell KH, Koester LA, Sides BA. Increasing lumbar lordosis of adult spinal deformity patients via intraoperative prone positioning. Spine (Phila Pa 1976) 2009;34:2406-12. DOI PubMed

25. Lee SK, Lee SH, Song KS, et al. Lumbar lordosis of spinal stenosis patients during intraoperative prone positioning. Clin Orthop Surg 2016;8:65-70. DOI PubMed PMC

26. Fei H, Li WS, Sun ZR, Jiang S, Chen ZQ. Effect of patient position on the lordosis and scoliosis of patients with degenerative lumbar 
scoliosis. Medicine (Baltimore) 2017;96:e7648. DOI PubMed PMC

27. Yson SC, Sembrano JN, Santos ER, Luna JT, Polly DW Jr. Does prone repositioning before posterior fixation produce greater lordosis in lateral lumbar interbody fusion (LLIF)? J Spinal Disord Tech 2014;27:364-9. DOI PubMed

28. Blizzard DJ, Vovos TJ, Gallizzi MA, et al. Interval effect of prone repositioning for posterior spinal instrumentation after lateral interbody fusion. $J$ Spine Neurosurg 2016;5:1. DOI

29. Guiroy A, Carazzo C, Camino-Willhuber G, et al. Single-position surgery versus lateral-then-prone-position circumferential lumbar interbody fusion: a systematic literature review. World Neurosurg 2021;151:e379-86. DOI PubMed

30. Sellin JN, Mayer RR, Hoffman M, Ropper AE. Simultaneous lateral interbody fusion and pedicle screws (SLIPS) with CT-guided navigation. Clin Neurol Neurosurg 2018;175:91-7. DOI PubMed

31. Huntsman KT, Riggleman JR, Ahrendtsen LA, Ledonio CG. Navigated robot-guided pedicle screws placed successfully in singleposition lateral lumbar interbody fusion. J Robot Surg 2020;14:643-7. DOI PubMed PMC

32. Spitz SM, Sandhu FA, Voyadzis JM. Percutaneous "K-wireless" pedicle screw fixation technique: an evaluation of the initial experience of 100 screws with assessment of accuracy, radiation exposure, and procedure time. J Neurosurg Spine 2015;22:422-31. DOI PubMed

33. Been E, Kalichman L. Lumbar lordosis. Spine J 2014;14:87-97. DOI PubMed

34. Macario A. What does one minute of operating room time cost? J Clin Anesth 2010;22:233-6. DOI PubMed

35. Tan JM, Macario A. How to evaluate whether a new technology in the operating room is cost-effective from society's viewpoint. Anesthesiol Clin 2008;26:745-64, viii. DOI PubMed

36. Lucio JC, Vanconia RB, Deluzio KJ, Lehmen JA, Rodgers JA, Rodgers W. Economics of less invasive spinal surgery: an analysis of hospital cost differences between open and minimally invasive instrumented spinal fusion procedures during the perioperative period. Risk Manag Healthc Policy 2012;5:65-74. DOI PubMed PMC

37. Hiyama A, Sakai D, Sato M, Watanabe M. The analysis of percutaneous pedicle screw technique with guide wire-less in lateral decubitus position following extreme lateral interbody fusion. J Orthop Surg Res 2019;14:304. DOI PubMed PMC

38. Castro WH, Halm H, Jerosch J, Malms J, Steinbeck J, Blasius S. Accuracy of pedicle screw placement in lumbar vertebrae. Spine (Phila Pa 1976) 1996;21:1320-4. DOI PubMed

39. Belmont PJ Jr, Klemme WR, Dhawan A, Polly DW Jr. In vivo accuracy of thoracic pedicle screws. Spine (Phila Pa 1976) 2001;26:2340-6. DOI PubMed

40. Mason A, Paulsen R, Babuska JM, et al. The accuracy of pedicle screw placement using intraoperative image guidance systems. $J$ Neurosurg Spine 2014;20:196-203. DOI PubMed

41. Schwarzenbach O, Berlemann U, Jost B, et al. Accuracy of computer-assisted pedicle screw placement. An in vivo computed tomography analysis. Spine (Phila Pa 1976) 1997;22:452-8. DOI PubMed

42. Esses SI, Sachs BL, Dreyzin V. Complications associated with the technique of pedicle screw fixation. A selected survey of ABS members. Spine (Phila Pa 1976) 1993;18:2231-8; discussion 2238-9. DOI PubMed

43. Hiyama A, Katoh H, Sakai D, Sato M, Tanaka M, Watanabe M. Accuracy of percutaneous pedicle screw placement after singleposition versus dual-position insertion for lateral interbody fusion and pedicle screw fixation using fluoroscopy. Asian Spine J 2021. DOI PubMed

44. Sarwahi V, Wendolowski SF, Gecelter RC, et al. Are we underestimating the significance of pedicle screw misplacement? Spine (Phila Pa 1976) 2016;41:E548-55. DOI PubMed

45. Aoude AA, Fortin M, Figueiredo R, Jarzem P, Ouellet J, Weber MH. Methods to determine pedicle screw placement accuracy in spine surgery: a systematic review. Eur Spine J 2015;24:990-1004. DOI PubMed

46. Söyüncü Y, Yildirim FB, Sekban H, Ozdemir H, Akyildiz F, Sindel M. Anatomic evaluation and relationship between the lumbar pedicle and adjacent neural structures: an anatomic study. J Spinal Disord Tech 2005;18:243-6. PubMed

47. Laudato PA, Pierzchala K, Schizas C. Pedicle screw insertion accuracy using O-arm, robotic guidance, or freehand technique: a comparative study. Spine (Phila Pa 1976) 2018;43:E373-8. DOI PubMed

48. Kim BD, Hsu WK, De Oliveira GS Jr, Saha S, Kim JY. Operative duration as an independent risk factor for postoperative complications in single-level lumbar fusion: an analysis of 4588 surgical cases. Spine (Phila Pa 1976) 2014;39:510-20. DOI PubMed

49. Abbasi H, Murphy CM. Economic performance of oblique lateral lumbar interbody fusion (OLLIF) with a focus on hospital throughput efficiency. Cureus 2015;7:e292. DOI PubMed PMC

50. Glassman SD, Berven S, Bridwell K, Horton W, Dimar JR. Correlation of radiographic parameters and clinical symptoms in adult scoliosis. Spine (Phila Pa 1976) 2005;30:682-8. DOI PubMed

51. Glassman SD, Bridwell K, Dimar JR, Horton W, Berven S, Schwab F. The impact of positive sagittal balance in adult spinal deformity. Spine (Phila Pa 1976) 2005;30:2024-9. DOI PubMed

52. Tan SB, Kozak JA, Dickson JH, Nalty TJ. Effect of operative position on sagittal alignment of the lumbar spine. Spine (Phila Pa 1976) 1994;19:314-8. DOI PubMed

53. Peterson MD, Nelson LM, Mcmanus AC, Jackson RP. The effect of operative position on lumbar lordosis: a radiographic study of patients under anesthesia in the prone and 90-90 positions. Spine 1995;20:1419-24. PubMed

54. Acosta FL, Liu J, Slimack N, Moller D, Fessler R, Koski T. Changes in coronal and sagittal plane alignment following minimally invasive direct lateral interbody fusion for the treatment of degenerative lumbar disease in adults: a radiographic study. J Neurosurg Spine 2011;15:92-6. DOI PubMed

55. Uribe JS, Myhre SL, Youssef JA. Preservation or restoration of segmental and regional spinal lordosis using minimally invasive interbody fusion techniques in degenerative lumbar conditions: a literature review. Spine (Phila Pa 1976) 2016;41 Suppl 8:S50-8. 
DOI PubMed

56. Rothrock RJ, McNeill IT, Yaeger K, Oermann EK, Cho SK, Caridi JM. Lumbar lordosis correction with interbody fusion: systematic literature review and analysis. World Neurosurg 2018;118:21-31. DOI PubMed

57. Hiyama A, Katoh H, Sakai D, Sato M, Tanaka M, Watanabe M. Comparison of radiological changes after single- position versus dualposition for lateral interbody fusion and pedicle screw fixation. BMC Musculoskelet Disord 2019;20:601. DOI PubMed PMC 